\title{
Cultura de segurança do paciente no transplante renal no oeste catarinense
}

\author{
Patient safety culture in kidney transplant patients in western Santa Catarina
}

\section{Cultura de seguridad del paciente en el trasplante renal en el oeste de Santa Catarina}

\section{Neriane Fatima Piana Pavan 1}

Aline Lima Pestana Magalhães ${ }^{2}$

Débora Fernanda Poncio ${ }^{3}$

Rosana Amora Ascari ${ }^{3}$

Patrícia Daiane Zanin ${ }^{3}$

Neide da Silva Knihs ${ }^{2}$

Olvani Martins Silva ${ }^{3}$

\section{Descritores}

Segurança do paciente; Transplante renal; Cultura organizacional; Equipe de assistência ao paciente

\section{Keywords}

Patient safety; Kidney transplantation;

Organizational culture; Patient care team

\section{Descriptores}

Seguridad del paciente; Trasplante de riñón; Cultura organizacional; Grupo de atención al paciente

\section{Submetido}

16 de Setembro de 2018

\section{Aceito}

2 de Maio de 2019

\section{Resumo}

Objetivo: Avaliar a cultura de segurança do paciente no perioperatório de transplante renal pela equipe multidisciplinar atuante nesse cenário. Métodos: Estudo transversal com 33 profissionais de saúde, que responderam ao questionário "Safety Attitudes Questionnaire", traduzido para a língua portuguesa. A coleta de dados foi em setembro de 2016 em um hospital público no oeste catarinense. Para análise dos dados utilizou-se Teste te análise de variância ANOVA $f$, um valor $\mathrm{p} \leq 0,05$ foi considerado significativo.

Resultados: 0 escore médio dos domínios avaliados variou 62,4 para Condicões de Trabalho, a 84,2 para Satisfação no trabalho. A percepção positiva da cultura de segurança foi evidenciada neste estudo nos domínios Satisfação do trabalho e Percepcão do estresse com médias de $83,8 \pm 15$ e $78,6 \pm 15$, respectivamente. A associação entre os domínios e as variáveis de caracterização da equipe multidisciplinar foi significativa entre 0 domínio Clima de trabalho em equipe e cargo $(\mathrm{p}=0,05)$. As demais variáveis não apresentaram significância estatística.

Conclusão: Quatro dos seis domínios avaliados obtiveram escores negativos, apontando a necessidade de estratégias voltadas à cultura de segurança efetiva aos pacientes no perioperatório de transplante.

\section{Abstract}

Objective: To evaluate the patient safety culture in the perioperative renal transplant period within the multidisciplinary team working in this setting.

Methods: A cross-sectional study with 33 health professionals, who responded to the "Safety Attitudes Questionnaire", translated into Portuguese. The data collection occurred in September of 2016, in a public hospital, in western Santa Catarina state. The t-test and analysis of variance (ANOVA f) was used for data analysis, and the $p$-value $\leq 0.05$ was considered significant.

Results: The mean score of the domains evaluated ranged from 62.4, for working conditions, to 84.2 for job satisfaction. The positive perception of the safety culture was evidenced in this study in the areas of job satisfaction and stress recognition, with means of $83.8 \pm 15$ and $78.6 \pm 15$, respectively. The association between the domains and the characterization variables of the multidisciplinary team was significant for teamwork climate and position ( $p=0.05)$. The other variables did not present statistical significance.

Conclusion: Four of the six domains evaluated showed negative scores, pointing to the need for strategies aimed toward an effective safety patient culture in the perioperative transplant period.

\section{Resumen}

Objetivo: evaluar la cultura de seguridad del paciente en el perioperatorio de trasplante renal por el equipo multidisciplinario que actúa en este escenario.

Métodos: estudio transversal con 33 profesionales de la salud, que respondieron al cuestionario "Safety Attitudes Questionnaire", traducido al portugués. La recolección de datos fue en septiembre de 2016 en un hospital público en el oeste del estado de Santa Catarina. Para analizar los datos, se utilizó el test-T y análisis de varianza ANOVA f, un valor $p \leq 0,05$ fue considerado significativo.

Resultados: la puntuación promedio de los dominios evaluados varió 62,4 en Condiciones de trabajo, a 84,2 en Satisfacción en el trabajo. La percepción positiva de la cultura de seguridad fue observada en este estudio en los dominios Satisfacción en el trabajo y Reconocimiento de estrés, con promedio de $83,8 \pm 15$ y 78,6 \pm 15 , respectivamente. La asociación entre los dominios y las variables de caracterización del equipo multidisciplinario fue significativa entre el dominio Clima de trabajo en equipo y cargo $(p=0,05)$. Las demás variables no presentaron significación estadística.

Conclusión: cuatro de los seis dominios evaluados obtuvieron puntuación negativa, lo que indica la necesidad de estrategias orientadas a la cultura de seguridad efectiva para los pacientes en perioperatorio de trasplante.

\section{Autor correspondente}

Olvani Martins da Silva

https://orcid.org/0000-0002-4285-3883

E-mail: olvanims@hotmail.com;

olvani.silva@udesc.br

\section{DOI}

http://dx.doi.org/10.1590/1982-

0194201900055

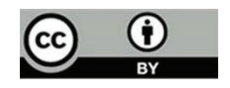

\section{Como citar:}

Pavan NF, Magalhães AL, Poncio DF, Ascari RA, Zanini PD, Knihs NS, et al. Cultura de segurança do paciente no transplante renal no oeste catarinense. Acta Paul Enferm. 2019;32(4):398-405. 


\section{Introdução}

Uma temática mundialmente debatida é a cultura de segurança do paciente. $\mathrm{Na}$ área da saúde é um princípio fundamental e um requisito primordial para a qualidade do cuidado, e para que este possa ser proporcionado de forma correta é necessário adquirir uma cultura de segurança, em que profissionais e serviços compartilhem práticas, valores, atitudes e condutas que possibilitem substituir a culpa e a punição pela oportunidade de aprender com as próprias falhas, e assim melhorar o cuidado em saúde possibilitando a garantia da segurança dos pacientes. ${ }^{(1)}$

A cultura de segurança do paciente está associada à capacidade de adaptação das instituiçóes de saúde em relação aos riscos humanos e operacionais inerentes ao processo de trabalho. ${ }^{(2,3)}$ Nesse sentido, a segurança do paciente vem ao encontro da qualidade na assistência, que é o grau de atendimento a padróes estabelecidos, frente às normas e protocolos que organizam as açôes de práticas assim como os conhecimentos técnicos e científicos atuais. ${ }^{(4)}$

A cultura de segurança do paciente tem instigado as instituiçóes a prestarem um cuidado seguro a fim de obter resultados adequados ao paciente sem causar qualquer risco de dano. Observa-se na literatura que essa temática tem sido foco de estudos nacionais e internacionais, principalmente nos contextos da Unidade de Terapia Intensiva Adulto, Emergência, Unidades de Clínica Médica e Cirúrgica, Atenção Primária, nas unidades que realizam Transplante de Medula Óssea. ${ }^{(5-9)}$ No entanto, observa-se uma lacuna no conhecimento quando se associa essa temática ao processo de doação e transplante de órgãos.

Para que ocorra o sucesso do transplante é imprescindível manter a qualidade do cuidado oferecido ao paciente, seja por meio da orientação da equipe assistencial quanto aos cuidados fundamentais inerentes a esse tipo de procedimento, ou ao aperfeiçoamento das técnicas cirúrgicas e busca de melhores práticas de cuidado, evitando a propagação de infecções, sinais e sintomas de rejeição ${ }^{(10)}$ e eventos indesejáveis no período perioperatório.

No Brasil, assim como em outros países tem sido desenvolvidas diversas açóes sobre a qualidade e segurança do paciente relacionadas ao processo de transplante, dentre essas se destacam: capacitaçôes das equipes, gestão de resultados, implantação de ferramentas de qualidade, rastreamento de eventos adversos e, em especial açôes assistenciais no atendimento ao paciente no sentido de melhorar a qualidade de vida e sobrevida do enxerto, bem como a efetividade no transplante. ${ }^{(11-14)}$

Neste sentido, considera-se de extrema relevância o estudo da cultura de segurança do paciente no transplante renal, uma vez que a equipe de saúde é desafiada a garantir um cuidado de qualidade ${ }^{(15)}$ e seguro ao paciente, durante o período de permanência no ambiente hospitalar para transplantação.

Diante do exposto formulou-se a seguinte questão de pesquisa: como a equipe multidisciplinar que presta assistência aos pacientes no período perioperatório de transplante renal percebem a cultura de segurança do paciente no ambiente de trabalho?

$\mathrm{O}$ estudo teve como objetivo avaliar a cultura de segurança do paciente no período perioperatório de transplante renal pela equipe multidisciplinar atuante nesse cenário.

\section{Métodos}

Estudo transversal, desenvolvido em um hospital público no Oeste de Santa Catarina, com coleta de dados em setembro de 2016. A amostra foi composta por todos os profissionais integrantes da equipe multidisciplinar que presta assistência direta ao paciente no período perioperatório de transplante renal.

Os critérios de inclusão foram ser enfermeiros, técnicos de enfermagem, e médicos residentes que prestam assistência ao paciente submetido ao transplante renal, que atuam nos setores de Terapia Intensiva, Centro Cirúrgico, Emergência, Comissão Intra-Hospitalar de Doação de Órgãos e Tecidos para Transplante (CIHDOTT) e Clínica Privativa, nos turnos matutino, vespertino e noturno e que aceitaram participar do estudo.

Foram excluídos do estudo profissionais em férias, licença do trabalho ou que estavam cobrindo férias no período da coleta de dados. O número total de profissionais na instituição é de 439 de 
enfermagem, fizeram parte da amostra 33 participantes. Trata-se de uma amostra não probabilística intencional, visto que se buscou entrevistar somente profissionais que atuam na assistência ao processo de transplante.

A coleta de dados foi realizada por meio do questionário o Safety Attitudes Questionnaire (SAQ), criado em 2006, traduzido para a língua portuguesa e adaptado transculturalmente para o Brasil em 2011. ${ }^{(16)}$

$\mathrm{O}$ instrumento contém perguntas que abrangem várias áreas da cultura de segurança do paciente, proporcionando um detalhamento que auxilia a identificação de áreas específicas com aspectos positivos e áreas que necessitam de melhorias. Composto por 41 questôes objetivas de fácil entendimento, dividido em duas partes: uma delas é composta por dados dos profissionais (sexo, profissão e tempo de experiência na especialidade). A outra é composta por questóes que englobam os seis domínios: clima de trabalho em equipe, clima de segurança, satisfação no trabalho, percepção do estresse, percepção da gestão da unidade e do hospital e condições de trabalho. ${ }^{(16)}$

As respostas a cada uma das questóes seguem uma escala Likert de cinco pontos: discordo totalmente (A), discordo um pouco (B), neutro (C), concordo um pouco (D), concordo totalmente (E) e não se aplica. A pontuação final do instrumento varia de 0 a 100 , onde zero representa a pior percepção do clima de segurança e 100 representa a melhor percepção. Os valores são considerados positivos quando a pontuação é maior ou igual a 75 . Consequentemente a pontuação é ordenada da seguinte forma: discordo totalmente (A) é igual a 0 pontos; discordo um pouco (B) é igual a 25 pontos; neutro (C) é igual a 50 pontos; concordo parcialmente (D) é igual a 75 pontos e concordo totalmente (E) é igual a 100 pontos. ${ }^{(16)}$ Para interpretar as questóes do instrumento, torna-se necessário agrupar seus itens em cada dimensão.

Para a coleta de dados, os pesquisadores entraram em contato com a enfermeira responsável pelas unidades mencionadas para agendar data e horário adequados para apresentação dos objetivos e metodologia do estudo. Naquele momento os que aceitaram participar do estudo, receberam o Termo de Consentimento Livre e Esclarecido (TCLE) e o ins- trumento. Após 20 minutos, as pesquisadoras retornaram a unidade para recolhimento dos instrumentos. Para aqueles que não efetuaram devolutivas, foi estipulado nova data e horário para recolhimento.

Os dados foram digitados no programa Excel $^{\oplus}$, posteriormente importados e analisados utilizando o programa Statistical Package for the Social Sciences (SPSS) versão 20.0, para a estatística descritiva.

Utilizou-se a estatística descritiva, e as variáveis categóricas foram expressas por frequências e percentuais, as variáveis contínuas com distribuição normal foram apresentadas por média e desvio padrão. Utilizou-se o teste Kolmogorov-Smirnov para teste de normalidade. A comparação das médias de grupos de duas categorias utilizou-se o Teste $t$, para variáveis com três ou mais grupos e, utilizou-se análise de variância ANOVA, um valor $\mathrm{p} \leq 0,05$ foi considerado significativo.

O projeto atendeu os preceitos éticos que envolvem pesquisa com seres humanos sendo aprovado sob o parecer $n^{\circ} 1.686 .546$, CAAE 55740816.1.0000.0118 de 17 de agosto de 2016 .

\section{Resultados}

Dos 33 participantes do estudo verificou-se que a maioria dos profissionais corresponde à categoria de auxiliar e técnico de enfermagem (66,7\%), seguida por enfermeiros $(27,3 \%)$. Houve predominância do sexo feminino, totalizando $84,8 \%$. Em relação ao local de trabalho, $58 \%$ desenvolviam suas atividades no centro cirúrgico e $27 \%$ nas clínicas de internação, sendo que $36,4 \%$ trabalhavam no turno matutino. Quanto ao tempo de experiência desses profissionais, obteve-se que a maioria $(27,3 \%)$ atua entre cinco a dez anos e 45,4\% trabalhavam na área de atenção ao adulto e a criança de acordo com a tabela 1 .

Em relação aos domínios do $\mathrm{SAQ}$, ao avaliar o clima de trabalho em equipe, observa-se que os maiores escores estiveram relacionados ao item, "Eu tenho o suporte necessário de outros membros da equipe para cuidar dos pacientes" com a média de 81,0 e ao item, "Nesta unidade, as discordâncias são resolvidas de modo adequado (ex: não quem está certo, mas o que é melhor para o paciente)" com 
Tabela 1. Características sociodemográficas da equipe multidisciplinar atuante no transplante renal

\begin{tabular}{|c|c|}
\hline Variável & $\mathrm{n}(\%)$ \\
\hline \multicolumn{2}{|l|}{ Cargo } \\
\hline Médico residente & $2(6,1)$ \\
\hline Enfermeiro & $9(27,3)$ \\
\hline Auxiliar e Técnico de Enf. & $22(66,7)$ \\
\hline \multicolumn{2}{|l|}{ Gênero } \\
\hline Masculino & $5(15,2)$ \\
\hline Feminino & $28(84,8)$ \\
\hline \multicolumn{2}{|l|}{ Local de trabalho } \\
\hline Centro Cirúrgico & 19(58) \\
\hline Clínicas & $9(27)$ \\
\hline UTI & $4(12)$ \\
\hline Pronto Socorro (PS) & $1(3)$ \\
\hline \multicolumn{2}{|l|}{ Turno de trabalho } \\
\hline Manhã & $12(36,4)$ \\
\hline Tarde & $8(24,2)$ \\
\hline Noite & $7(21,2)$ \\
\hline Diurno & $4(12,1)$ \\
\hline \multicolumn{2}{|l|}{ Tempo de especialidade } \\
\hline 6-11 meses & $3(9,1)$ \\
\hline 1-2 anos & $6(18,2)$ \\
\hline 3-4 anos & $8(24,2)$ \\
\hline 5-10anos & $9(27,3)$ \\
\hline 11-20 anos & $3(9,1)$ \\
\hline 21 anos ou mais & $3(9,1)$ \\
\hline \multicolumn{2}{|l|}{ Atuação principal } \\
\hline Adulto & $7(21,2)$ \\
\hline Adulto e infantil & $15(45,4)$ \\
\hline
\end{tabular}

média de 77,3\%. O escore mais baixo esteve relacionado à "Nesta área, é difícil falar se eu percebo um problema com o cuidado ao paciente" com média de 56,7. Mas, os resultados de todas as médias dos escores obtiveram um resultado negativo com a média total da dimensão clima de trabalho de 72 , uma vez que para os valores serem considerados positivos a pontuação tem que ser maior ou igual a 75 .

$\mathrm{Na}$ "Dimensão de Clima de Segurança” o item "Eu me sentiria seguro se fosse tratado aqui como paciente" obteve média de 71,9, e o escore que apresentou média mais negativa foi "Eu recebo retorno adequado sobre meu desempenho" com média de 48,6. A média total da dimensão de clima de segurança foi negativa, obtendo uma pontuação de 64,4.

A "Dimensão de Satisfação no Trabalho" o escore que mais se destacou foi "eu gosto do meu trabalho" com a média de 91,4, e o escore de menor média foi “o moral nesta aérea é alto" com a média de 70,2. Entre todos os escores a média total da dimensão da satisfação no trabalho foi positiva com 84,2.

Na dimensão "Percepção do Estresse", o escore mais alto pertence à afirmação "quando minha carga de trabalho é excessiva, meu desempenho é prejudicado" com a média 85,1 e o escore mais baixo "O cansaço prejudica meu desempenho durante situaçôes de emergência” com a média 66,7. A média total dessa dimensão foi positiva com resultado de 77.

O resultado da dimensão "Percepção de Gerência Hospitalar" o item mais pontuado foi "recebo informaçóes adequadas e oportunas sobre eventos que podem afetar meu trabalho" com média de 70,5 e o de menor escore foi "nessa área a equipe (número e qualificação) é suficiente para lidar com o número de pacientes" com a média de 49. A média total da percepção da gerência geral do hospital foi de 59,4. Quando verificado a percepção da gerência da CIHDOTT, o escore que mais se destacou foi "administração está fazendo um bom trabalho" com a média de 82,0. A média total da percepção da gerência da CIHDOTT foi de 64,5.

De acordo com o domínio "Condiçóes de Trabalho" os escores dos itens não apresentaram resultados positivos. Todos os escores estiveram abaixo de 75. O escore com o resultado mais negativo foi "toda a informação necessária para decisóes diagnósticas e terapêuticas está disponível rotineiramente para mim”, média de 60,1. A média total das condiçôes de trabalho foi de 62,4 apresentando resultado negativo.

Para a "Média Geral dos Domínios da Avaliação da Cultura de Segurança do Paciente no Transplante Renal" através dos resultados obtidos pelos domínios do SAQ, observa-se que os domínios Satisfação no trabalho e Percepção do estresse obtiveram médias superiores a $75(83,8 \pm 15$ e $78,6 \pm 15)$ respectivamente. Os demais domínios apresentaram avaliações negativas para cultura de segurança, sendo as piores avaliaçóes para percepçáo da gerência da unidade e clima de trabalho, conforme apresentado na tabela 2 .

Tabela 2. Média Geral dos Domínios de acordo com a avaliação do SAQ

\begin{tabular}{lccc}
\hline Domínios & Média & DP $( \pm)$ & Mediana \\
\hline Clima de trabalho em equipe & 71,4 & 16,8 & 70,3 \\
Clima de segurança & 65,9 & 17,3 & 67,8 \\
Satisfação no trabalho & 83,8 & 15 & 87,5 \\
Percepção do estresse & 78,6 & 15 & 81,2 \\
Percepção de Gerencia(Geral) & 65,9 & 11,2 & 66,6 \\
Percepção ClHD0TT & 63,2 & 13,6 & 66,6 \\
Condições de trabalho & 63,2 & 22,5 & 75,0 \\
\hline
\end{tabular}

DP- desvio padrão 
E ao verificar a associação entre os domínios do SAQ e as variáveis de caracterização da equipe multidisciplinar, observa-se que foi significativa a associação entre o domínio Clima de trabalho em equipe e cargo $(\mathrm{p}=0,05)$. As demais variáveis náo apresentaram significância estatística de acordo com a tabela 3 .

Tabela 3. Associação entre os Domínios e as Variáveis de caracterização dos profissionais

\begin{tabular}{lcccc}
\hline & \multicolumn{4}{c}{$p$-value } \\
\cline { 2 - 5 } Domínios & Gênero* $^{*}$ & $\begin{array}{c}\text { Tempo de } \\
\text { especialidade }\end{array}$ & $\begin{array}{c}\text { Local de } \\
\text { trabalho }\end{array}$ & Cargo $^{* *}$ \\
\hline Clima de trabalho em equipe & 0,32 & 0,65 & 0,10 & 0,05 \\
Clima de segurança & 0,58 & 0,81 & 0,07 & 0,08 \\
Satisfação no trabalho & 0,97 & 0,65 & 0,32 & 0,18 \\
Percepção do estresse & 0,41 & 0,33 & 0,35 & 0,20 \\
Percepção de Gerencia Geral & & 0,51 & 0,88 & 0,91 \\
Percepção de Gerência CIHDOTT & & 0,12 & 0,99 & 0,19 \\
Condições de trabalho & 0,60 & 0,58 & 0,41 & 0,07 \\
\hline Nota: ${ }^{*} p$-value do teste $t{ }^{* \star}{ }^{*} p$-value do teste ANOVA & & &
\end{tabular}

Nota: ${ }^{*} p$-value do teste $t,{ }^{\text {**}} p$-value do teste ANOVA

\section{Discussão}

Os resultados desse estudo indicam que aspectos relevantes da cultura da segurança do paciente no transplante renal no oeste de Santa Catarina, precisam ser trabalhados. A avaliação da média dos escores demonstra que das seis dimensóes avaliadas, apenas duas obtiveram valores superiores a 75, valor considerado, neste estudo, como mínimo positivo para a cultura de segurança.

De acordo com os resultados a maioria dos profissionais pertence à categoria dos técnicos e auxiliares de enfermagem seguida por enfermeiros. Observa-se na literatura que estudos que utilizaram o mesmo instrumento também obtiveram em suas amostras a maior participação da equipe de enfermagem: 93,49\%, ${ }^{(17)} 45 \% .^{(18)}$ Em estudos desenvolvidos apenas com a equipe de enfermagem, predominou a participação dos técnicos e auxiliares de enfermagem: $68,2 \% .^{(19)}$

Mais da metade dos profissionais que atuam na especialidade de transplante renal possui experiência profissional superior a cinco anos. Salienta-se que é extrema importância que o enfermeiro tenha conhecimento nas práticas do transplante, pois elas são essenciais para uma assistência segura prestada ao paciente. $\mathrm{O}$ profissional tem que saber ampliar seu conhecimento com a finalidade de promover a saúde do paciente transplantado, sendo necessário o aperfeiçoamento contínuo. Vale salientar que o profissional demonstra um importante processo educativo no período perioperatório de transplante renal. ${ }^{(20)}$

Em relação a dimensão "Clima de trabalho", que avalia a qualidade do relacionamento e a colaboração entre os profissionais, é uma das variáveis que influencia o desempenho da organização dos objetivos propostos. Nas instituiçóes de saúde é essencial que exista um ambiente propício à integração das equipes multiprofissionais, bem como promoção da qualidade de vida no trabalho, motivação, satisfação e possibilidades de desenvolvimento. ${ }^{(21)}$

A percepção dos profissionais sobre o "Clima de segurança" encontra-se abaixo do esperado corroborando com resultados obtidos em estudo semelhante realizado em hospital terciário, no município de Vitória, Espírito Santo; ${ }^{(22)}$ em quatro hospitais privados no município de Uberaba, Minas Gerais ${ }^{(17)}$ e em um hospital de ensino em São Paulo. ${ }^{(23)} \mathrm{O}$ clima de segurança envolve a relação entre implementação da cultura de segurança por estar associada diretamente com a relação, integraçáo da equipe de saúde e diminuição dos eventos adversos. ${ }^{(17)}$

Além disso, o clima de segurança também apresenta reflexóes aos trabalhadores demonstrando à adequada importância da segurança na organização, sendo um princípio que atribui para a diminuição das lesôes acidentais. Em um estabelecimento, admite-se perceber os pontos fracos e fortes do desempenho do profissional de saúde, podendo então permitir a identificação dos campos mais pretensiosos, com a intenção de instituir e delinear intervençôes. ${ }^{(17)}$

Considerando as informaçóes obtidas, faz-se necessário que a instituição invista na mudança de cultura e estimule os profissionais a reconhecer e socializar seus erros na equipe, no intuito de fortalecer o aprendizado do sujeito na coletividade. Contudo, ressalta-se a necessidade de desenvolver a cultura de notificação desses eventos no sentido de obter maior segurança na assistência ao paciente submetido ao transplante renal.

O domínio "Satisfação do trabalho da equipe" foi o escore que apresentou valor mais positivo para 
a cultura de segurança. Dados semelhantes foram identificados em outros estudos nacionais. ${ }^{(22-24)}$

Os resultados mais frequentes da satisfação no trabalho incidem sobre a produtividade, função do seu papel, absenteísmo, rotatividade, cidadania organizacional, saúde e bem-estar, satisfação na vida e dos clientes. A satisfaçáo profissional favorece atitudes positivas consigo e com os outros e contribui para maior participação do profissional em seu ambiente laboral. Nesse sentido, melhora o desempenho profissional e consequentemente fortalece a cultura de segurança. ${ }^{(25)}$

Corroborando com os dados do presente estudo no que se refere à satisfação no trabalho, no Japão foi conduzida uma pesquisa com 537 enfermeiros de dez hospitais, investigando três hipóteses relacionadas a segurança. Os achados apontaram que os procedimentos hospitalares de segurança do paciente têm um impacto na satisfação profissional dos enfermeiros, assim como a autopercepçáo da autonomia do enfermeiro em seu espaço laboral está positivamente associada à satisfação no trabalho. ${ }^{(26)}$

A dimensão "Percepção do estresse" obteve resultado positivo com o segundo maior escore de todas as dimensóes. É possível reconhecer como os fatores estressores influenciam negativamente no desempenho do trabalho. O ambiente hospitalar possui aspectos muito específicos que favorecem a excessiva carga de trabalho, como a existência de regime de turnos e plantóes que permite a ocorrência de duplos empregos e longas jornadas de trabalho, situaçôes que tem levado diversos profissionais ao estresse excessivo e ao abandono da profissão. ${ }^{(27)}$

A sobrecarga de trabalho provoca descontentamento do profissional em relaçẫo à gestão hospitalar, ou seja, a percepção da gerência é avaliada de forma negativa. A enfermagem possui um alicerce na parte da gerência para realizar o ajustamento do quantitativo de recursos humanos, respaldada pela legislação, por meio da Resoluçáo 543 de 2017 do Conselho Federal de Enfermagem (COFEN). ${ }^{(28)}$ Em muitas instituiçóes de saúde há falta de recursos humanos o que contribui para o surgimento de riscos para a segurança do paciente. ${ }^{(29)}$

A dimensão "Percepção da gerência do hospital" teve sua média com escores de resultados negativos, decorrente das duas categorias com escores negativos. $\mathrm{O}$ envolvimento dos gestores frente à mudança do cenário de segurança nas instituições de saúde torna-se fundamental no sentido de conhecer os desafios que a equipe enfrenta diariamente. ${ }^{(15)}$ Neste contexto, uma via de comunicaçáo efetiva com os níveis hierárquicos pode permitir a construção da confiança entre todos os envolvidos.

$\mathrm{O}$ apoio da gestáo para a segurança do paciente é uma dimensão no âmbito da organização hospitalar. ${ }^{(29)}$ Os baixos escores evidenciados através dos profissionais neste estudo sugere que a promoção da segurança do paciente não é adequadamente percebida pela gestão hospitalar.

A dimensão que apresentou o menor escore, "condiçóes de trabalho", avalia a percepçáo dos profissionais quanto à qualidade do seu ambiente de trabalho, corroborando com achados encontrados em estudo desenvolvido na região sudeste do Brasil. ${ }^{(23)}$ Um escore baixo para essa dimensão, também foi identificado em estudo realizado na Suécia que utilizou o SAQ, onde a média para esse escore foi de 66,8 . Vale ressaltar que os autores abordoram profissionais da equipe cirúrgica e gestores. ${ }^{(30)}$

As condiçóes de trabalho no âmbito hospitalar vêm sendo consideradas inadequadas neste cenário decorrentes da falta de qualificação, baixos salários, quantitativo de profissionais insuficiente, exposição a fatores de riscos, o que repercute na qualidade assistencial dispensada ao usuário e compromete a satisfação profissional. ${ }^{(31)}$

A "Média Geral dos Domínios" quando se comparou os escores das dimensôes, demonstrou que a "Percepção de Gerência da CIHDOTT" e a "Condições de trabalho" tiveram uma perspectiva menos positiva que as demais.

No processo de trabalho é primordial um bom gerenciamento, infraestrutura de qualidade, disponibilidade de informação para tomada de decisão, equipamentos eficazes e com boa manutençáo, gerenciamento de conflitos e supervisão adequada para que se possibilite melhor desempenho e produtividade no trabalho. ${ }^{(9)}$

De uma forma geral, quando observado todos os domínios do SAQ em relação a "Média Geral dos Domínios" o domínio "Satisfação no trabalho" 
apresentou o maior escore. Ou seja, os dados apontam que os profissionais gostam do seu trabalho independente de algumas restriçóes, com uma experiência positiva no local de trabalho, através de fatores que influenciam a motivação.

Por fim, ao verificar a associação entre os domínios do SAQ, houve uma associação significativa entre o domínio Clima de trabalho em equipe e cargo, isso equivale dizer que dependendo do cargo assumido na instituição, existe um melhor entrosamento na equipe de trabalho.

O clima de trabalho precisa ser adequado ao máximo, para que exista um apoio entre a equipe. E para que os mesmos venham exercer as perspectivas de suas atividades, é de suma importância que haja uma satisfação no cargo que desempenham, pois isso reflete diretamente na assistência e no entrosamento das equipes de trabalho. ${ }^{(15)} \mathrm{O}$ clima no trabalho é importante para que haja um resultado esperado pelos colaboradores para manter uma harmonia no local.

Na perspectiva da cultura de segurança, o estudo apresenta a necessidade e a importância da satisfação no trabalho, trabalho em equipe, entrosamento da equipe e bom relacionamento com gestores. Esses pontos são fundamentais a serem gerenciados por profissionais que atuam na administraçáo das instituiçóes de saúde e nas unidades, no sentido de propor um ambiente de trabalho acolhedor, humano e participativo viabilizando uma assistência segura e efetiva contribuindo para resultados favoráveis ao paciente submetido ao transplante.

Assim, compreende-se o papel estratégico que o enfermeiro possui ao gerenciar uma unidade de transplante, visto ser esse profissional que atua diretamente na gestão da equipe, a qual desenvolve assistência direta ao paciente. Frente a essa visão, destaca-se a importância do profissional enfermeiro estar capacitado e habilitado para atuar junto a sua equipe nas unidades de transplante. $\mathrm{O}$ empoderamento deste profissional na temática transplante viabiliza melhor qualidade de vida ao transplantado, maior tempo de sobrevida ao enxerto, além de eficácia e segurança a equipe e paciente neste processo. ${ }^{(32-34)}$

As limitaçóes deste estudo consistem na escassez de literatura científica com este enfoque, o que impossibilita comparaçóes e tamanho da amostra pequena.

\section{Conclusão}

Os resultados do presente estudo evidenciaram que a avaliação das atitudes de cultura de segurança na instituição é percebida como positiva nos domínios "satisfação do trabalho" e "percepção do estresse". Essas dimensóes cooperam com a segurança dos pacientes no período perioperatório de transplante renal. As demais dimensóes necessitam de intervenção cuidadosa, no sentido de estimular os profissionais a se envolver e desenvolver atitudes de segurança no processo de transplantação. Os piores escores foram observados nos domínios "condiçôes de trabalho" e "percepção da gerência”. Tais resultados subsidiam gestores e profissionais assistenciais na elaboração de estratégias para estabelecer medidas que favoreçam a cultura de segurança do paciente e a gestão do cuidado.

\section{Colaborações}

Pavan NFP, Magalhães ALP, Poncio DF, Ascari RA, Zanini PD, Knihs NS e Silva OM declaram que contribuíram com a concepção do estudo, análise e interpretação dos dados, redação do artigo, revisão crítica relevante do conteúdo intelectual e aprovação da versão final a ser publicada.

\section{Referências}

1. WegnerW, Silva SC, Kantorski KJ, Predebon CM, Sanches MO, Pedro EN. Educação para cultura da segurança do paciente: Implicações para a formação profissional. Esc Anna Nery. 2016;20(3):e20160068.

2. World Health Organization (WHO). WHO Guidelines on Hand Hygiene in Health Care. First Global Patient Safety Challenge - Clean Care is Safer Care [Internet]. Geneva:WHO; 2004 [cited 2018 Mar 15]. Available from: http:// apps.who.int/iris/bitstream/handle/10665/44102/9789241597906_eng. pdf;jsessionid=E254EFFAA8CF30381ADC63F1E9DA3E4F?sequence=1

3. Caldana G, Guirardello EB, Urbanetto JS, Peterlini MA, Gabriel CS. Brazilian network for nursing and patient safety: challenges and perspectives. Texto Contexto Enferm. 2015;24(3):906-11.

4. Vituri DW, Matsuda LM. Content validation of quality indicators for nursing care evaluation. Rev Esc Enferm USP. 2009; 43(2):429-37. 
5. Minuzzi AP, Salum NC, Locks MO. Assessment of patient safety culture in intensive care from the health team's perspective. Texto Contexto Enferm. 2016; 25(2):e1610015.

6. Reis FF, Oliveira KF, Luiz RB, Barichello E, Cruz LF, Barbosa MH. Cultura de segurança em unidades de terapia intensiva. Rev Enferm Atenção Saúde. 2017; 6(2):34-48

7. Macedo TR, Rocha PK, Tomazoni A, Souza S, Anders JC, Davis K. The culture of patient safety from the perspective of the pediatric emergency nursing team. Rev Esc Enferm USP. 2016;50(5):75662

8. Mesquita KO, Silva LC, Lira RC, Freitas CA, Lira GV. Patient safety in primary health care: an integrative review. Cogitare Enferm. 2016; 21(2):1-8

9. Fermo VC, Radünz V, Rosa LM, Marinho MM. Patient safety culture in a bone marrow transplantation unit. Rev Bras Enferm. 2015; 68(6):82734.

10. Correa AP, Brahm MM, Teixeira CC, Ferreira SL, Manfro RC, Lucena AF, Echer IC. Complications during the hospitalization of kidney transplant recipients. Rev Gaúcha Enferm. 2013;34(3):46-54.

11. Ohler L. Quality assessments for organ transplantation. Acta Paul Enferm. 2017; 30(2):III-V.

12. Santiago JF, Selow ML. Gestão de qualidade em pacientes transplantados. Vitrine Prod Acad. 2015;3(2):354-9.

13. Siqueira MM, Araujo CA, Roza BA, Schirmer J. Indicadores de eficiência no processo de doação e transplante de órgãos: revisão sistemática da literatura. Rev Panam Salud Publica. 2016;40(2):90-7.

14. Magalhães AL, Lanzoni GMM Knihs NS, Silva EL, Erdmann AL. Patient safety in the process of organ and tissue donation and transplant. Cogitare Enferm. 2017;(22)2:e45621.

15. Cavalcante AK, Cavalcante FA, Pires DC, Batista EM, Nogueira LT. Nursing perception of safety culture: integrative review. J Nurs UFPE Online. 2016;10(10):3890-7.

16. Carvalho RE, Cassiani SH. Cross-cultural adaptation of the Safety Attitudes Questionnaire - Short Form 2006 for Brazil. Rev Lat Am Enfermagem. 2012;20(3):575-82.

17. Barbosa MH, Floriano DR, Oliveira KF, Nascimento KG, Ferreira LA. Patient safety climate at a private hospital. Texto Contexto Enferm. 2016; 25(3):1-8.

18. Patel S, Wu AW. Safety culture in Indian Hospitals: a cultural adaptation of the safety attitudes questionnaire. J Patient Safety. 2016;12(2):7581.

19. Marinho MM, Radünz V, Barbosa SFF. Assessment of safety culture by surgical unit nursing teams. Texto Contexto Enferm. 2014; 23(3):58190.
20. Inácio LA, Montezeli JH, Sade PM, Caveião C, Hey AP. Nurse performance in the patient's discharge guidance after kidney transplant. Rev Enferm UFSM. 2014;4(2):323-31.

21. Chaves JA, Guimarães MG. Analysis of organizational climate in the operating room of a university hospital in the city of Manaus. Rev Farol. 2016;1(1):206-19.

22. Matiello RD, Lima EF, Coelho MC, Oliveira ER, Leite FM, Primo CC. Patient safety culture from the perspective of nurses. Cogitare Enferm. 2016;21(Spe):1-9.

23. Tondo JC, Guirardello EB. Perception of nursing professionals on patient safety culture. Rev Bras Enferm. 2017;70(6):1355-60.

24. Carvalho REF, Arruda LP, Nascimento NK, Sampaio RL, Cavalcante ML, Costa AC. Assessment of the culture of safety in public hospitals in Brazil. Rev Lat Am Enfermagem. 2017;25:e2849.

25. Alves DF, Guirardello ED. Nursing work environment, patient safety and quality of care in pediatric hospital. Rev Gaúcha Enferm. 2016; 37(2):e58817.

26. Inoue T, Karima R, Harada K. Bilateral effects of hospital patient-safety procedures on nurses' job satisfaction. Int Nurs Rev. 2017; 64(3):437-45.

27. Puene-Palacios KE, Porto JB, Martins MC. Emersion through combining levels in Organizational and Work Psychology. Rev Psicol Organ Trab. 2016;16(4):358-66.

28. Conselho Federal de Enfermagem (COFEN). Resolução COFEN 543/2017. Atualiza e estabelece parâmetros para o Dimensionamento do Quadro de Profissionais de Enfermagem nos serviços/locais em que são realizadas atividades de enfermagem [Internet]. Brasília (DF): COFEN; 2017 [citado 2018 Feb 21]. Disponível em: http://www.cofen. gov.br/resolucao-cofen-5432017_51440.html

29. Oliveira FB, Costa AC, Alves DL, França JF, Macedo MS, Santos RD. Relationship between work overload and medication administration errors in hospital care. Facema. 2016;2(2):325-34.

30. Göras C, Unbeck M, Nilsson U, Ehrenberg A. Interprofessional team assessments of the patient safety climate in Swedish operating rooms: a crosssectional survey. BMJ Open. 2017;7:e015607.

31. Fontinhas JE, Carloso JM. Stress in nursing work. Rev Uningá. 2017; $51: 78-86$

32. Santos CM, Kirchmaier FM, Silveira WJ, Arreguy-Sena C. Perceptions of nurses and clients about nursing care in kidney transplantation. Acta Paul Enferm. 2015;28(4):337-43.

33. Fagherazzi V, Trecossi SP, Oliveira RM, Souza JES, Sauer Neto M, Santos RP. Permanent education on organ/tissue donation with community health agents. J Nurs UFPE on line. 2018;12(4):1133-8.

34. Moreira WC, Barbosa TM, Ribeiro WR, Damasceno CK, Alencar DC, Vieira SK. Assistência de enfermagem no processo de doação de órgãos e transplantes. Rev Pre Infec Saúde. 2016;2(1-2):32-42. 